\title{
Scene but Not Heard: Collecting Local Music
}

\section{By Sean Luyk}

Local and regional music collections are a topic of increasing interest in music librarianship in recent years. With a panel devoted exclusively to this topic at the 2013 Music Library Association conference, papers published in Fontes ${ }^{1}$ and Notes, ${ }^{2}$ and the current issue of CAML Review devoted to this theme, it appears that music librarians may be refocusing their efforts on local music. This paper provides an overview of the discourse on local music collecting practices in libraries, and addresses the challenges and opportunities inherent in this endeavor. The scenes approach from popular music studies is presented as one possible body of theory useful for music librarians interested in collecting local music, followed by an account of the author's experience in developing a local music collection at the University of Alberta Music Library.

\section{Music Librarians on Local Music Collections}

Collections of local materials in libraries are certainly nothing new, and neither are collections with a significant music component. There is a well-documented history in the music library literature on the importance of local music collections, and impassioned calls for music librarians to pay attention to the music of their own communities. What follows is an overview of the literature on local music collecting from the perspective of music librarians, put into a contemporary context.

Writing on behalf of the Library of Congress Music Division in a 1940 volume of Notes, Harold Spivacke stresses the responsibility libraries have in preserving and providing access to music collections of local interest. Spivacke states that "[the role of the library] is to collect, preserve and make available a record of the past and present life of the community it serves." ${ }^{3}$

Sean Luyk is the Music Librarian at the University of Alberta Music Library. This article is an expanded version of his presentation at the 2012 International Association of Music Libraries, Archives and Documentation Centres conference in Montreal, Quebec.

1. See Priscilla Winling, "Bringing the Local Music Scene to the Public Libraries Network of Strasbourg: A Live Collection," Fontes Artis Musicae 59, no. 2 (2012): 127-33.

2. See John Vallier, "Sound Archiving Close to Home: Why Community Partnerships Matter," Notes 67, no. 1 (2010): 39-49.

3. Harold Spivacke, "The Collection of Musical Material of Local Interest," Notes 8 (1940): 50. 
For many libraries, a collecting philosophy centered on documenting local culture is a cornerstone of their mandate, but for others it may be of only marginal importance. Public libraries and archives have traditionally been more likely to contain extensive local music collections than academic libraries, although there are notable examples of local music collections in academic libraries as well. ${ }^{4}$ Regardless of the type of library, it is likely that we all have local musical cultures deserving of our attention and professional stewardship.

Spivacke lists the various types of materials librarians should collect to document the musical life of their communities (for example: concert programs, archives of performing groups, and scores of community composers) and explains how to acquire and process these materials and build relationships with community musicians and organizations. The materials described likely already exist in many of our collections, or are at least readily available to us should we be interested. Spivacke's suggestions for what to collect still apply today, and serve as good starting points for creating local music collections. His suggestions are, however, representative of a time when music libraries focused most of their collecting efforts on Western Art Music traditions, and in the case of local music, the concert life of a given community. Interest in other musics was only beginning to take hold, and Spivacke acknowledges this fact with reference to folk music, stating "I should like to look forward to the day when all the music librarians of the country will take a more active role in the preservation and dissemination of this form of musical expression." ${ }^{5}$

A common thread in Spivacke's article is the importance of local collections in informing a national documentary heritage, because "a truly national outlook must be based on the interests of all the localities that make up our nation." ${ }^{6}$ Spivacke continues by noting how local music collections contribute to the larger goal of comprehensive national collections. By having a local music collection, "the librarian so engaged, is preserving for all the country, the documentary evidence of one of the most important elements of our nation's culture."7 This observation is timely given the recent dismantling of national libraries and archival institutions under austerity, with music and arts divisions often being the first to suffer. This is particularly true in Canada in recent years with major cuts made to Library and Archives Canada, including

4. For example, the extensive holdings of the Wisconsin Music Archives housed in the Mills Music Library, University of Wisconsin-Madison (http://music.library.wisc.edu/wma/index.html) and the Saskatchewan Music Collection housed in the University of Saskatchewan Education and Music Library (http://library.usask.ca/education/SaskMusic.php)

5. Spivacke, "Collection of Musical Material," 53.

6. Ibid., 49.

7. Ibid., 54. 
the discontinuation of the National Archival Development Program, ${ }^{8}$ downsizing of the Music Division through attrition, the freeze on acquisitions of materials from private individuals, and the general trend away from subject specialization. It becomes increasingly difficult to piece together a Canadian musical heritage from contributions of local and regional collections when it is doubtful that there will continue to be a national outlook to contribute to.

Furthermore in the Canadian context, in March of 2012 the satellite music libraries of the Canadian Broadcasting Corporation ( $C B C$ ) were required to expediently weed their sound recording collections and consolidate them with those at their national headquarters in Toronto and Montréal. The rationale for this move according to $\mathrm{CBC}$ management was that "the $\mathrm{CBC}$ has been relying less and less on $\mathrm{CD}$ s and albums and more on digitized music, like much of the industry." ${ }^{9}$ Although this may be true, there is a risk that much local content was lost in this speedy consolidation, and there is now a void between local musicians and local CBC music libraries. Luckily, the University of Alberta Music Library was able to obtain some of the discards from the Edmonton CBC Music Library (as were other CAML institutions from their CBC libraries) and arrange for the ongoing deposit of promotional CDs (which the local CBC Music Library is no longer accepting). With yet another vital collector of local musical heritage being undermined, the responsibility is offloaded to other libraries in the community.

Twenty-five years after Spivacke's article in Notes, Dena Epstein revisits his call for the creation of music collections of local interest, highlights the importance of local collections in contributing to the documentation of a national musical culture, provides collecting strategies, and describes the types of materials that should be collected. Echoing Spivacke's call for local collections in contributing to national music histories, Epstein writes, "the local history of music ... has more than a regional interest, since definitive treatments of music . . cannot be written until local studies provide the groundwork." ${ }^{10}$ Epstein's article reveals a change in collecting practices that was occurring at the time of its writing. Aside from collecting materials that document the past, Epstein reminds librarians to collect current materials, which will prove to be of use in the future. Furthermore, to cope with the "ever-increasing bodies of material not needed to meet current demands," ${ }^{11}$ Epstein suggests grouping local music materials into archival collections, rather than treating them as individual items, which she argues is

8. In April 2012, the National Archival Development Program (NADP) was discontinued. The NADP "helps archivists in all our communities to acquire, preserve, and make available the invaluable records of Canada's past and present for today's citizens and for all future generations." Quoted from Canadian Council of Archives, "Memorandum on the Elimination of the National Archival Development Program," accessed March 11, 2013, http://www.cdncouncilarchives.ca/CCAFactSheet v1.2Updated EN.pdf.

9. CBC spokesman Chris Ball. Quoted in Guy Dixon, "CBC Dismantling LP, CD Archives," Globe and Mail (Toronto, ON), Jan. 17, 2012.

10. Dena J. Epstein, “On Collecting Materials for Local Music Histories," Notes 24, no. 1 (1967): 18.

11. Ibid., 20. 
acceptable to both the researcher and the librarian. The difficulty in balancing the current and future uses of collections is still prevalent today, and is particularly challenging when dealing with local music collections. The music librarian developing a local music collection should make every effort to collect the present, but also seek out historical materials that document the music life of their community.

Epstein and Spivacke's insights on the importance of local music collections, and practical strategies for collecting local music, are still useful today. What is perhaps needed is a modernized understanding of the importance of local music collections, taking into account the current challenges in their creation, including the difficulty in doing retrospective collecting, the technologies of distribution as a barrier to collecting, and the expanded scope of music collections. What follows is a description of some of the current challenges the music librarian faces in creating a local music collection.

\section{Contemporary Challenges}

One of the major challenges in developing local music collections is related to the limited work carried out by some of our predecessors in this area. In many cases local music may have been out of scope or simply ignored for reasons of workload, budget, or interest. It is likely that not all music librarians have grasped the importance of documenting their local musical cultures in the service of comprehensive national collections, or have considered local music to be within the realm of their collection development responsibilities.

Reflecting on his experience of building a local music collection in the Leicester Reference Library, Michael Rafferty remarks that the strength of a local music collection depends heavily on the efforts of our predecessors and their collecting philosophies. Rafferty writes, "the local studies librarians of the 50 s and 60 s were not exactly quick off the mark when it came to youth culture ... not many - probably none, in fact - were rushing down to the record shop to secure a copy of their local skiffle group's latest 78. . . We ignore the low-brow at our peril."12 Rafferty was bemoaning the difficulty of playing "catch-up" in his local music collection; local popular music had not really been collected by his library in the past despite the fact that vibrant music scenes existed in his community, including skiffle. He was now faced with having to catch up with the music scene of Leicester in his collection, and was presented with recordings of skiffle music that were now pricey collector's items. The scenario that Rafferty recounts is likely familiar to many librarians wanting to start a local music collection from the ground up.

12. Michael Rafferty, "Compiling a Comprehensive Local Music Archive - Some Problems," Local Studies Librarian 20, no. 2 (2001): 12. 
Although the aversion to collecting materials from youth culture has probably long passed for most music librarians, other very practical reasons for not doing so are likely to persist, such as budget, workload, institutional support, and the difficulty in balancing the current and future collection needs of users.

Another challenge in creating local music collections that is related to the work done by our predecessors is the issue of collection mandates. Music libraries generally have not collected popular and traditional musics until relatively recently, let alone local materials of these musics. The collection mandates of music libraries undoubtedly reflect the mandates of their parent institutions and the discourses under which they operate. ${ }^{13}$ However, as institutions change and their mandates become more representative of the general culture, so does acceptance for the widening of collection mandates. Tom Moore makes a good point on how the broadening of music curricula has resulted in broader collections in music libraries. Moore writes:

Throughout most of the LP era, many music collections restricted their scope to the western European canon, narrowly defined, with little interest in the erudite musical production of countries outside the central triumvirate of France, Germany, and Italy, and with even less interest in popular music, whether from the NATO bloc or elsewhere. The eighties and nineties saw a substantial evolution in the music under consideration even in the more conservative musical institutions. ${ }^{14}$

Despite the evolution of music programs in the 80 s and 90 s that Moore describes and the influence this had on the collecting mandates of music libraries, it is clear that collection gaps are bound to persist, resulting in music libraries having to do significant retrospective collections work to keep current with the expanding needs of their users. This problem is augmented when it comes to local music, which is likely still out of scope, or only narrowly defined, in many music libraries' collection mandates. This is perhaps in part a result of the reluctance of music libraries to collect materials representative of popular culture, a large part of which may fall under the category of local music. Tom Caw claims that "there seems to be a consensus among popular music studies practitioners that most academic libraries have insufficient holdings of sound recordings, videos, academic journals, trade journals, consumer magazines, and other similar materials." ${ }^{15}$ With the growth and acceptance of popular music studies in the academy, it is important for music libraries to embrace the area, and local music collections are one way (in

13. For a description of how institutional mandates are reflected in the collection mandates of music libraries, see Sanna Talja, Music, Culture, and the Library: An Analysis of Discourses (Lanham, MD: Scarecrow Press, 2001).

14. Tom Moore, "Sound Recordings," Notes 56, no. 3 (2000): 639.

15. Tom S. Caw, "Popular Music Studies Information Needs: You Just Might Find . . . , Popular Music and Society 27, no. 1 (2004): 52. 
addition to expanded popular music collections generally) to better serve the needs of popular music scholars.

Furthermore, the role music libraries have historically played in enforcing the Western musical canon and representing the history of music through the contents of their collections should not be overlooked, and should be continually questioned. As Lisa Hooper writes, "by collecting and preserving sound, collectors in essence define what will become an integral part of the historical record which future researchers, historians, cultural anthropologists, musicologists, ethnomusicologists, will all turn to in the process of writing an authoritative, legitimated history." ${ }^{16}$ The music librarian engaged in creating a local music collection is helping to ensure that the history their collection presents to future users includes the accomplishments of local musicians, and honestly reflects the local culture in which the library is situated.

In addition to the challenges presented by the changing interests of the users music libraries serve, technological changes also present music librarians with problems in developing local music collections. More local music is being created than ever before given the low cost and minimal technical know-how required, and the easy ability to distribute music freely on the internet. Roger Levesque, writing about the local music scene in the Edmonton Journal, observes in 2006 that "as the volume of non-mainstream music releases grows larger and larger every year, finding a good selection of that same music is getting harder and harder." ${ }^{17}$ Seven years later, Levesque's observation is even more true; with local musicians foregoing physical media and instead releasing their music online only, and libraries not yet having a legal and practical way to acquire it, collecting local music is paradoxically stalled despite its high availability. This should not discourage librarians from continuing to pursue local collecting, however; it should prompt us to adapt to changing modes of distribution in service to our local collections, and inspire us to take advantage of the increasing availability of local music materials. One such initiative in this regard is the MLA Digital Audio Collections Task Force, whose purpose was to explore solutions to the problem presented by digital music content that is "increasingly hampered both by license agreements with intermediary content aggregators and by restrictive language in end-user license agreements." ${ }^{18}$ The recommendations outlined in their report include collective license options using models already established for journal materials (such as the JSTOR and Portico/CLOCKSS models), independent negotiations between

16. Lisa Hooper, "Underwriting History: The Role of Sound Recording Collectors in Shaping the Historical Record," ARSC Journal 42, no. 1 (2011): 44.

17. Roger Levesque, "Live Music Scene Keeps Getting Better: But Fewer Stores Now Stock Non-Mainstream CD Releases," Edmonton Journal (Edmonton, AB), Dec. 26, 2006.

18. Music Library Association, "Digital Audio Collections Task Force 2011: Report to the Board of Directors," accessed March 15, 2013, http://www.musiclibraryassoc.org/uploadedFiles/About MLA/Annual Reports/Ad Hoc Reports/MLADigitalAudio Taskforce.pdf. 
libraries and license holders, and legislative efforts to make the law work in favour of the unique needs of music libraries. The work done in this regard influences much more than local music collecting, and offers promising strategies for obtaining the growing amount of local music materials being released in digital format only.

\section{The Scenes Approach}

In light of the importance of local music collecting and the need for practical solutions to deal with challenges common to this activity, it is also important to have a body of theory to draw upon when thinking about local music. In the following section I discuss theoretical perspectives on local music, and what they may offer music librarians in service to their local music collections. As I will demonstrate, the scenes approach from popular music studies can help us better understand what constitutes local music, and in turn make us better prepared to develop local collections of lasting interest.

Historically, the term "music scene" comes to us from the journalistic literature of the golden age of jazz. Richard Florida explains that the term has historically been used to describe "the musical genres associated with mid-20th-century crossroads music locations that brought diverse rural talent into contact with larger audiences, performance venues, recording studios, radio stations, managers, and record labels." ${ }^{19}$ This definition conjures up images of well-known music scenes in major metropolitan areas, whereby a location becomes known for a particular genre of music (for example Chicago blues, New Orleans jazz, and Nashville country). ${ }^{20}$ What this traditional definition of the music scene misses, however, is the diverse range of musical activities happening in any given locale; it also unfairly ignores the musical activities of smaller centres. To counter this, and other problematic constructions of the music scene, the scenes approach offers more nuanced understandings of local music.

The scenes approach arose out of scholars in the 1990s trying to grapple with issues of music and locality in an increasingly fragmented popular music industry where "alternative" music scenes were gaining in importance, and where traditional notions of the music scene were proving to be problematic. First used in an academic context by Will Straw in $1991{ }^{21}$ the scenes approach offers a holistic view of local music not bound by mainstream understandings of musical genre and location which are in fact often only commercial constructs. Straw defines

19. Richard Florida, Charlotta Mellander, and Kevin Stolarick, "Music Scenes to Music Clusters: The Economic Geography of Music in the US, 1970-2000," Environment \& Planning A 42, no. 4 (2010): 787.

20. Andy Bennett, "Consolidating the Music Scenes Perspective," Poetics 32, no. 3-4 (2004): 223.

21. Will Straw, "Systems of Articulation, Logics of Change: Communities and Scenes in Popular Music," Cultural Studies 5, no. 3 (1991): 368-88. 
the music scene as "that cultural space in which a range of musical practices coexist, interacting with each other within a variety of processes of differentiation, and according to widely varying trajectories of change and cross-fertilization." ${ }^{22}$

An influential collection of studies, which expands on Will Straw's work in the early 1990s, outlines three major types of music scenes: local, translocal, and virtual. Music created in the local scene refers to:

A focused social activity that takes place in a delimited space and over a specific span of time in which clusters of producers, musicians, and fans realize their common musical taste, collectively distinguishing themselves from others by using music and cultural signs often appropriated from other places, but recombined and developed in ways that come to represent the local scene ${ }^{23}$

The work of Bennett, Peterson, and others using the scenes approach ${ }^{24}$ mostly focuses on independent popular music scenes that operate outside of the standard channels of commercial distribution. The scenes approach does however provide many insights for music librarians attempting to grow their own local music collections regardless of the musical tradition in question, because it broadens the understanding of what local music can and should include, and its literature provides concrete examples of the documentation of local music scenes. It is an expanded definition of local music that considers what musical activities are going on in a given space and time from the perspective of both producers and consumers. It also allows us to consider music that originated elsewhere as still being local, as the scenes approach purports that music takes on the character of a given locale through processes of differentiation.

The scenes approach disavows the "subculture" label to describe divergent music scenes operating outside of the mainstream, which comes to us from a more traditional cultural studies approach. ${ }^{25}$ In fact, the scenes approach avoids the subculture label altogether in order to avoid the "centre-periphery" distinction where the "homogeneous" subculture is put in opposition to the supposedly "homogeneous" mainstream culture. The local music scene definition is drawn more from sociological conceptions of culture, in particular the work of

22. Ibid., 373.

23. Andy Bennett and Richard A. Peterson, "Introducing Music Scenes," in Music Scenes: Local, Translocal and Virtual, ed. Andy Bennett and Richard A. Peterson (Nashville: Vanderbilt University Press, 2004), 8.

24. Notable examples of works employing the scenes approach include Holly Kruse, Site and Sound: Understanding Independent Music Scenes (New York: Peter Lang, 2003), and John Connell and Chris Gibson, Sound Tracks: Popular Music, Identity, and Place (London: Routledge, 2003).

25. For example, Dick Hebdige's Subculture: The Meaning of Style, which explored Mod Culture in 1960s England 
Pierre Bourdieu on the field of cultural production, and the "art worlds" described by Becker. ${ }^{26}$ In this approach, culture operates within a field in which focus is not simply directed towards the creator, but operates within a larger, broader construction that includes the consumers of music and cultural intermediaries, and takes issues of class, gender, and ethnicity into account. What this means for local music collections in libraries is that instead of merely focusing our collecting efforts on local musical creators, we also consider large consumer and fan communities, producers, and other cultural intermediaries as integral parts in the operation of a given local music scene. From a practical standpoint, this approach offers music librarians multiple points of entry into their local music scenes, and flexibility in that local music can be defined in multiple ways, at different points in time.

It may seem daunting to consider the music scenes approach as a collecting strategy, given how broadly it allows local music to be defined and the level of cultural theory it draws upon. However, it is possible to put some parameters around the approach to make it manageable in a practical way. As Connell and Gibson write, "at the most basic level, before a 'sound' or 'scene' can develop, there should be both a 'critical mass' of active musicians or fans, and a set of physical infrastructures of recording, performance and listening ... spaces that allow for new musical practices." ${ }^{27}$ Since it is likely inconceivable to be able to identify and collect the output of every local music scene active in your community (especially in larger urban centres), it is a better strategy to look for those that have at least some staying power as evident by a critical mass of creators and consumers, venues catering to a given scene, and vibrant fan communities. Perhaps what can be taken from the local music scenes approach is that the musical life of the community you serve cannot be taken at face value. From a methodological perspective, the scenes approach is rooted in ethnographic methods and the belief that immersion in a musical culture is of primary importance in understanding it. Acceptance and adoption of this methodological framework by music librarians can be of great benefit in terms of outreach and in situating ourselves as leaders in the trend towards an embedded model of librarianship. The broader understanding of the way musical life and locality are mutually implicated, as outlined in the scenes approach, can help librarians to better collect and document the music of their communities.

26. Bennett and Peterson, "Introducing Music Scenes," 3.

27. John Connell and Chris Gibson, Sound Tracks: Popular Music, Identity, and Place (London: Routledge, 2003), 101. 


\section{Local Music Collecting - The University of Alberta Experience}

In the summer of 2011 the Edmonton Music Collection at the University of Alberta Music Library began to take shape. The impetus for the Edmonton Collection was a discussion I had with a colleague from the University of Alberta Science and Technology Library who had been a performing musician in Edmonton for over 25 years. We were discussing the small amount of local music materials in the collection, and how worthwhile it would be to develop this area further. He explained to me that he had wanted to do something like this for a long time, had contacts, knew the local independent music scene, and was eager to help. What started as a casual conversation has resulted in a partnership to develop a unique collection of local materials, and is now part of our regular collection development activities.

Previous efforts were made by my predecessors to collect music of the Province of Alberta, the output of major performing groups in the Edmonton region, and the musical output of University of Alberta musicians. A decision was made to focus future collecting efforts on the Edmonton region alone as our budget and resources do not warrant a province-wide collection. Materials in all formats with an Edmonton connection are in scope, including recordings of musicians and groups active in the region, music with an Edmonton connection in its subject matter, scores of Edmonton composers, writings about musical life in Edmonton, and other printed materials about Edmonton music. Much of the inspiration for this approach (aside from the local instead of regional focus) came from the excellent collection at the University of Saskatchewan Education and Music Library, described elsewhere in this issue as well as in a previous issue of the CAML Review. ${ }^{28}$ In determining which materials should be included in the collection, the biggest difficulty is when a musician leaves the Edmonton area and establishes their career somewhere else (or conversely, when a musician who records or performs primarily in Edmonton is based elsewhere).

Four times a year a local record store specializing in independent music of the Edmonton area sends us a list of the latest local music titles (mostly independent releases), as well as "musthaves" from the past of well-known musicians and performing groups with an Edmonton connection. Our library assistant then searches the catalogue to determine which titles we already own, and we ask the store to exchange these titles with other selections. We purchase the titles in person, which has the added benefit of developing a good working relationship with the owner and staff, and raises awareness of the collection to the larger musical community. We have also made a retrospective list of materials of local artists and performing groups for future

28. Richard Belford, "Building a Regional Music Collection: The Saskatchewan Experience," CAML Review 35, no. 1 (2007): 19-21, accessed March 21, 2013.

http://pi.library.yorku.ca/ojs/index.php/caml/article/view/2753/1958. 
purchase, and are gradually purchasing recordings and scores we do not already own from wherever we can find them (our donation backlog, flea markets, and online vendors). So far this has proven to be a good start to a comprehensive local music collection, but we still have much work to do.

One of the obvious limitations so far has been the focus on independent popular music. This is primarily due to the fact that our collection is lacking in these materials, and that Edmonton has a thriving local scene deserving a collection of its own. The output of classical performing groups is well represented in our collection already, and we plan to continue to obtain materials in this area, as well as identify and acquire materials from groups we have missed over the years. We also hope to broaden the scope of the collection to include archival materials from local artists and performing groups, by offering to act as the stewards of their records.

Items in the Edmonton Music Collection are sent to cataloguing accompanied by a flag instructing the cataloguer to add the following local (590) note: "UA Library copy in the Edmonton Music Collection." Various options were discussed to provide intellectual access to the collection including the use of custom subject headings and series statements. The decision to use a 590 note was made as it fit best into our established cataloguing workflows and use of 590 notes to identify named collections. We are continually identifying local music materials already in our collection, and retrospectively having the local note added. At the time of writing, the collection contains over 1000 items.

We are also creating a research guide specifically about the local music collection which could serve to highlight holdings, solicit donations, and provide enhanced access that the catalogue is not able to offer. We still have a number of local music materials that have accumulated over the past 40 years and need to be incorporated into the collection, including a pamphlet file that contains copies of programs of University of Alberta ensembles dating back to the 1950s; open reel tapes, cassettes, VHS tapes and CDs of University of Alberta ensembles dating back to the late 1960s; and various items such as performer scrapbooks, printed ephemera of performing groups, and non-commercially produced recordings. The ultimate goal of the Edmonton Music Collection is to collect materials documenting local musical cultures as comprehensively as possible, and we feel we are off to an excellent start. 


\section{Works Cited}

Belford, Richard. "Building a Regional Music Collection: The Saskatchewan Experience." CAML Review 35, no. 1 (2007): 19-21. Accessed March 21, 2013. http://pi.library.yorku.ca/ojs/index.php/caml/article/view/2753/1958.

Bennett, Andy. "Consolidating the Music Scenes Perspective." Poetics 32, no. 3-4 (2004): 22334.

Bennett, Andy, and Richard A. Peterson, eds. Music Scenes: Local, Translocal and Virtual. Nashville: Vanderbilt University Press, 2004.

Canadian Council of Archives. "Memorandum on the Elimination of the National Archival Development Program." Accessed March 11, 2013. http://www.cdncouncilarchives.ca/CCAFactSheet v1.2Updated EN.pdf.

Caw, Tom S. "Popular Music Studies Information Needs: You Just Might Find . . " Popular Music And Society 27, no. 1 (2004): 49-54.

Connell, John, and Chris Gibson. Sound Tracks: Popular Music, Identity, and Place. London: Routledge, 2003.

Epstein, Dena J. “On Collecting Materials for Local Music Histories." Notes 24, no. 1 (1967): 1821.

Florida, Richard, Charlotta Mellander, and Kevin Stolarick. "Music Scenes to Music Clusters: The Economic Geography of Music in the US, 1970-2000." Environment \& Planning A 42, no. 4 (2010): 785-804.

Hooper, Lisa. "Underwriting History: The Role of Sound Recording Collectors in Shaping the Historical Record." ARSC Journal 42, no. 1 (2011): 43-49.

Kruse, Holly. Site and Sound: Understanding Independent Music Scenes. New York: Peter Lang, 2003.

Moore, Tom. "Sound Recordings." Notes 56, no. 3 (2000): 635-40.

Rafferty, Michael. "Compiling a Comprehensive Local Music Archive - Some Problems." Local Studies Librarian 20, no. 2 (2001): 12-13.

Spivacke, Harold. "The Collection of Musical Material of Local Interest." Notes 8 (1940): 49-54.

Straw, Will. "Systems of Articulation, Logics of Change: Communities and Scenes in Popular Music." Cultural Studies 5, no. 3 (1991): 368-88.

Talja, Sanna. Music, Culture, and the Library: An Analysis of Discourses. Lanham, MD: Scarecrow Press, 2001.

Vallier, John. "Sound Archiving Close to Home: Why Community Partnerships Matter." Notes 67, no. 1 (2010): 39-49. 